\title{
Simulation and Analysis of Modified DTC of PMSM
}

\author{
D. Kiran Kumar, G. Tulasi Ram Das \\ Department of Electrical and Electronics Engineering, JNTUH College of Engineering, India
}

\begin{tabular}{l} 
Article Info \\
\hline Article history: \\
Received Jun 5, 2017 \\
Revised Dec 23, 2017 \\
Accepted Jul 25, 2018 \\
\hline Keyword: \\
Hysteresis bands, \\
Modified DTC, \\
Percentage of THD, \\
Permanent magnent, \\
Synchronous motor, \\
PI controller, \\
The fast torque response.
\end{tabular}

\begin{abstract}
This research paper describes the simulation and analysis of the modified DTC for Surface mounted Permanent Magnet Synchronous Motor (SPMSM) using PI controller. Among all of the various drive systems,PMSM is widely used for accurate speed and torque control, with greater efficiency, superior torque to inertia and high power density. The Conventional DTC secheme widely used for this purpose but it is failed to achieve desirable performance of the system for which the modified DTC secheme is propsed.The modified DTC algorithm controls the voltage vectors, directly from a simple look up table depending on outcome of the torque and indirectly flux controllers. The overall drive system can be implemented in SIMULINK/MATLAB environment.The modified DTC is validated with loading conditions. The simulated results are focused on the speed, settling time at loaded conditions, torque and flux linkages ripple and THD in the phase current for modified DTC applied to SPMSM.
\end{abstract}

Copyright ()$^{\circ} 2018$ Institute of Advanced Engineering and Science. All rights reserved.

\section{Corresponding Author:}

D. Kiran Kumar,

Department of Electrical and Electronics Engineering,

Jawaharlal NehruTechnological University,

Hyderabad, Telangan State, India-500085, India.

Email: kirannkumar9@gmail.com

\section{INTRODUCTION}

The last few decades, Permanent Magnent Synchronous Motor (PMSM) has acquired more popularity in far ranging application and in the automation sector because of its compact size, high efficiency, small inertia and high reliability which is greater than the induction and dc motors [1]. It has similar properties like Wound Rotor Synchronous motor except that the PMSM has no damper windings and the Permanent magnets are used to provide the excitation to the motor instead of field winding [2].

The Direct Torque Control (DTC) is a viable control algorithm for SPMSM. It does not require current controller and no motor parameters except the stator resistance, which gives the more benifits such as less parameters dependency, simple implementation and fast dynamic torque response [3].The traditional DTC adopts hysteresis bands control strategy for implementation. But this method can not meet the system requirements for both the torque and flux linkage at the same time generates large fluctuations of flux linkage and torque by system which leads to problem of pulse current and causes switching noise due to change in switching frequency [4],[5].

In order to overcome these issues the modified DTC method is developed without using switching tables, to reduce the fluctuations of the torque and flux linkages of the system and THD \% in the current spectrum of stator winding is low.In addition to achieve the fast torque response with indirect flux controllers [6]. In this paper, first the mathematical modeling of PMSM has been developed. Then the simulation of modified DTC of PMSM with two level inverter is carried out using SIMULINK/MATLAB. 


\section{MATHEMATICAL MODELING OF PERMANENT MAGNET SYNCHRONOUS MOTOR}

The permanent magnets of PMSM are of a modern rare earth variety and it has high resistivity, so the induced currents of rotor are neglected. However the PMSM produces the rotor magnetic flux with permanent magnets attached to the rotor. It has superior advantages to obtain high efficiency. The stator of the PMSM and the Wound Rotor Synchronous Motor are same. The d-q reference frame theory offers significant control system design by transferring the stationary variables to rotating reference frame.

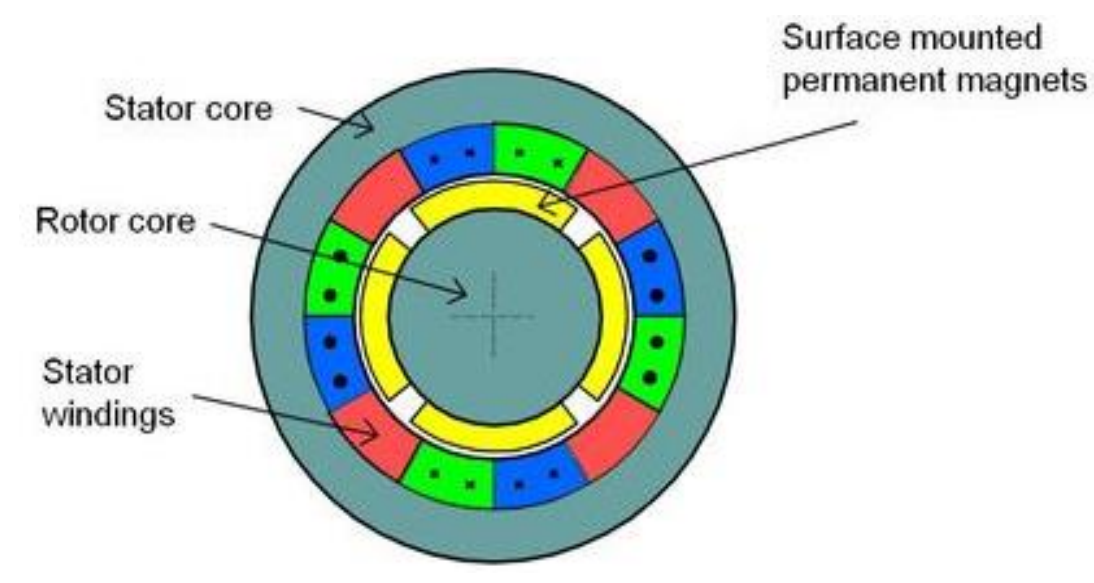

Figure 1. Cross sectional veiw of surface mounted perment magnet machine

Depending on d-q reference frame theory from Figure 2. the mathematical equations of PMSM [7] can be expressed as following as in.

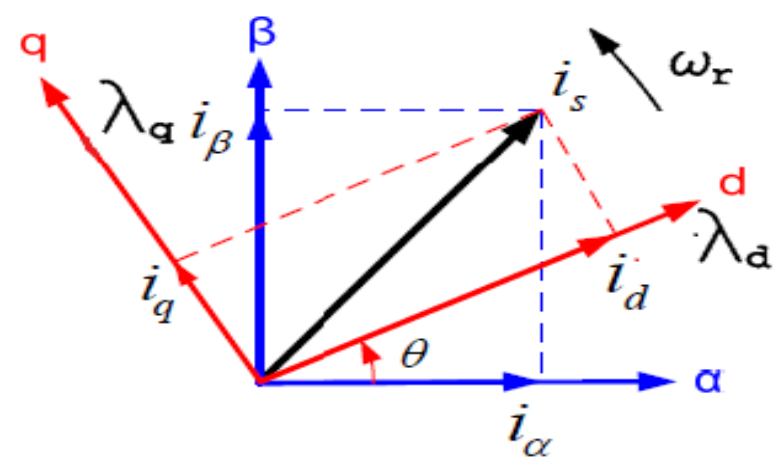

Figure 2. Stator and rotor flux linkages in different reference frames

$$
\begin{gathered}
\mathrm{V}_{\mathrm{d}}=\mathrm{R}_{\mathrm{d}} \mathrm{I}_{\mathrm{d}}+\frac{\mathrm{d} \lambda_{\mathrm{d}}}{\mathrm{dt}}-\omega_{\mathrm{r}} \lambda_{\mathrm{q}} \\
V_{q}=R_{q} I_{q}+\frac{d \lambda_{q}}{d t}+\omega_{r} \lambda_{d}
\end{gathered}
$$

where $R_{d}$ and $R_{q}$ are the Direct and Quadrature axis winding resistances which are equal and refered as Rs in the stator resistance. The excitation of PMSM can be modeled as a constant current sources and the quadrature current in the rotor is zero due to no flux along quadrature axis in the rotor. By this assumption, the flux linkages are derived as following as in

$$
\begin{aligned}
& \lambda_{d}=\mathrm{L}_{\mathrm{d}} \mathrm{I}_{\mathrm{d}}+\lambda_{\mathrm{f}} \mathrm{I}_{\mathrm{f}} \\
& \lambda_{\mathrm{q}}=\mathrm{L}_{\mathrm{q}} \mathrm{I}_{\mathrm{q}}
\end{aligned}
$$


where $\lambda_{\mathrm{f}}$ is rotor flux along $\mathrm{d}$ axis and $\mathrm{L}_{\mathrm{d}}$ and $\mathrm{L}_{\mathrm{q}}$ are the Direct and Quadrature axis synchronous inductance. For a surface mounted machine (SPMSM) with uniform air gap $\mathrm{L}_{\mathrm{d}}=\mathrm{L}_{\mathrm{q}}=\mathrm{L}_{\mathrm{s}}$. and Substituting equation (3) and (4) in equations (1) and (2) then obtained [8] as

$$
\begin{aligned}
& V_{d}=R_{s} I_{d}+L_{d}\left(\frac{d I_{d}}{d t}\right)-\omega_{r} L_{q} I_{\mathrm{q}} \\
& V_{q}=R_{s} I_{q}+L_{q}\left(\frac{d I_{q}}{d t}\right)+\omega_{r} L_{d} I_{d}+\omega_{r} \lambda_{\mathrm{f}} I_{f}
\end{aligned}
$$

The Electromagnetic torque developed by the motor is given by equation (7)

$$
T_{e}=\frac{3}{2} P\left(L_{d} I_{q} I_{d}+\lambda_{f} I_{q}-L_{q} I_{q} I_{d}\right)
$$

And the mechanical torque Te is expressed as equation (8)

$$
T e-T_{L}=B \omega_{m}+\frac{J \omega_{m}}{d t}
$$

Where $\mathrm{P}=$ no. of poles

$\lambda_{\mathrm{f}}=$ magnetic flux, $\mathrm{wb}$

$\omega_{\mathrm{r}}=$ rotor speed in electrical $\mathrm{rad} / \mathrm{s}$

$\mathrm{Te}=$ Electromagnetic torque, $\mathrm{Nm}$

$\mathrm{T}_{\mathrm{L}}=$ Load torque

$\mathrm{J}=$ Moment of Inertia

$\mathrm{B}=$ Friction coefficient

The stator fluxes of $\alpha-\beta$ axis for motor [9],[10] are given as equations (9) and (10)

$$
\begin{aligned}
& \lambda_{\alpha}=\int\left(\mathrm{V}_{\alpha}-\mathrm{R}_{\mathrm{S}} \mathrm{I}_{\alpha}\right) \mathrm{dt} \\
& \lambda_{\beta}=\int\left(V_{\beta}-R_{S} I_{\beta}\right) d t
\end{aligned}
$$

The stator fluxes of $\alpha-\beta$ axis are used for determine the sector of the flux vector and the circular trajectory of stator flux is divided into six sectors are referred to inverter voltage vectors. Then based on equations (9) and (10) the magnitude of the estimated stator flux and sector [5] are calculated as equation (11)

$$
\begin{aligned}
& \left|\lambda_{s}\right|=\sqrt{\lambda_{\alpha}{ }^{2}+\lambda_{\beta}^{2}} \\
& \theta_{s}=\tan ^{-1}\left(\frac{\lambda_{\alpha}}{\lambda_{\beta}}\right)
\end{aligned}
$$

\section{THE PRINCIPLE OF OPERATION OF MODIFIED DTC}

The basic working principle of operation of conventional DTC is based on the errors between estimated and reference values of torque and stator flux linkages. This method is very popular due to its simplicity, high efficiency and robustness. However, in traditional DTC the current controller is a not required. In this method, it generates large fluctuations of flux linkage and torque by motor which causes problem of current and switching noise due to higher switching frequency change.

The modified DTC method is implemented without using switching tables, hysteresis bands as Figure 3 shown below and the absensce of switching table and hysteresis bands significantly reduce the torque and flux linkage ripples. Moverever, the percentage of Total Harmonics Distortion of Stator winding current spectrum is low and it require less settling time for rotor speed when the load is applied.The fast torque response can be achieved with indirect flux controllers. 


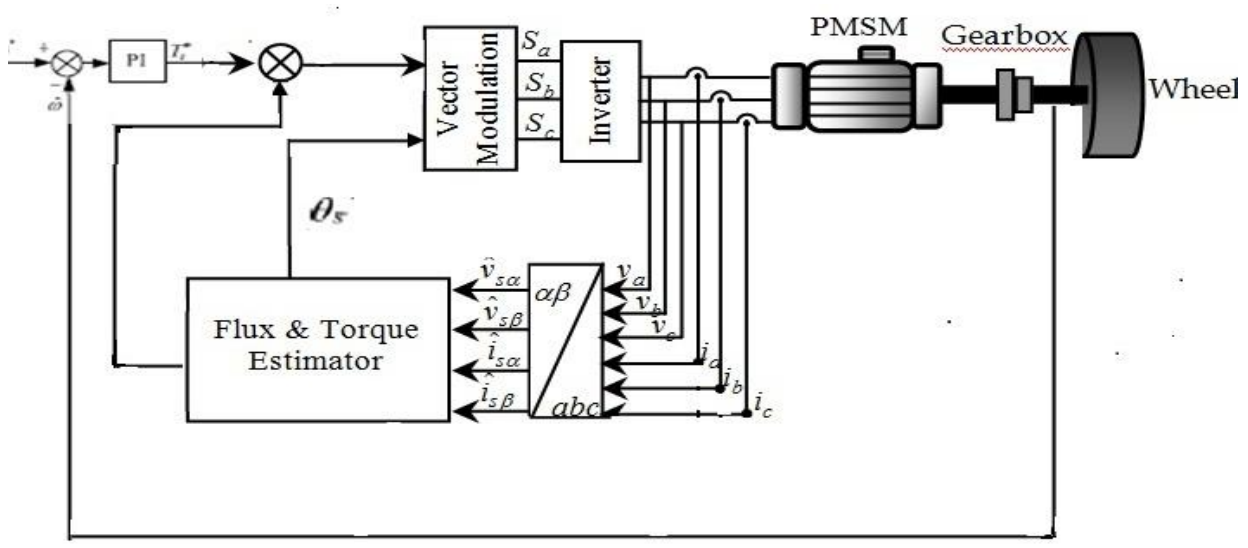

Figure 3. Schematic diagram of modified DTC of PMSM with PI controller using two levels Inverter

\subsection{Vector Modulation}

Vector modulation can be implemented with the torque comparator and sector which is determined from the stator flux vectors.Three blocks of Look Up Tables (2-D) are used for implementation of code with the switching states of two level voltage source inverter as shown in Figure 4. These are applied to the corresponding look up tables for all six sectors are in Figure 5.

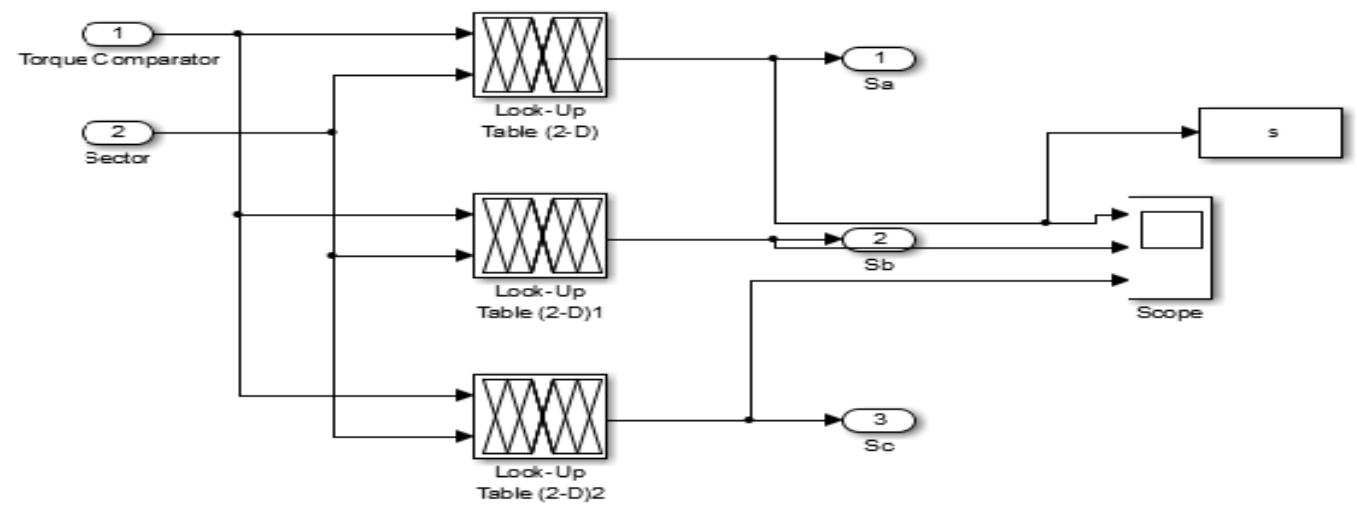

Figure 4. Implementation of vector modulation for modified DTC

Where in the sector selection of Space vector modulation for two level inverter [11] as in Figure 5

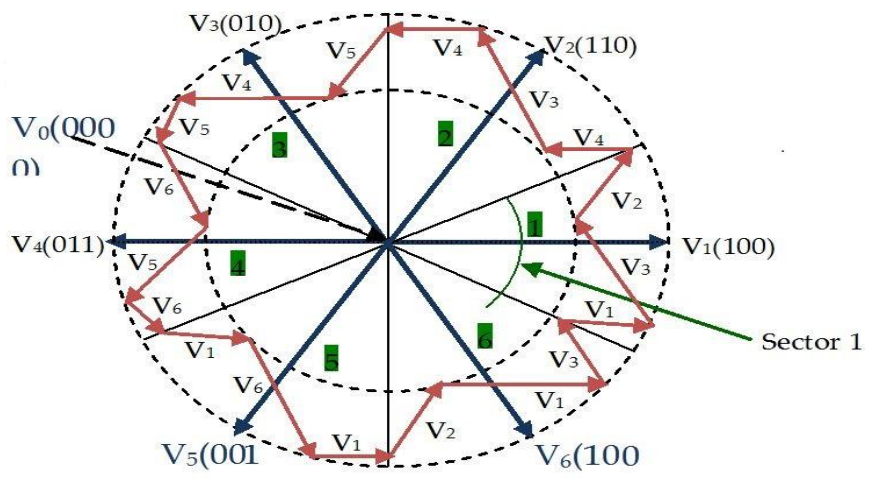

Figure 5. Sector selection of Space Vector Modulation 


\subsection{Two Level Voltage Source Inverter}

The circuit of a three phase two level VSI is shown in Figure 6. The input of circuit is DC voltage $V_{\mathrm{dc}}$ and the output voltages are applied to the SPMSM as load. The stator flux of a motor is controlled by voltage vectors. The rotation of stator flux is high then achieved the fast torque response.

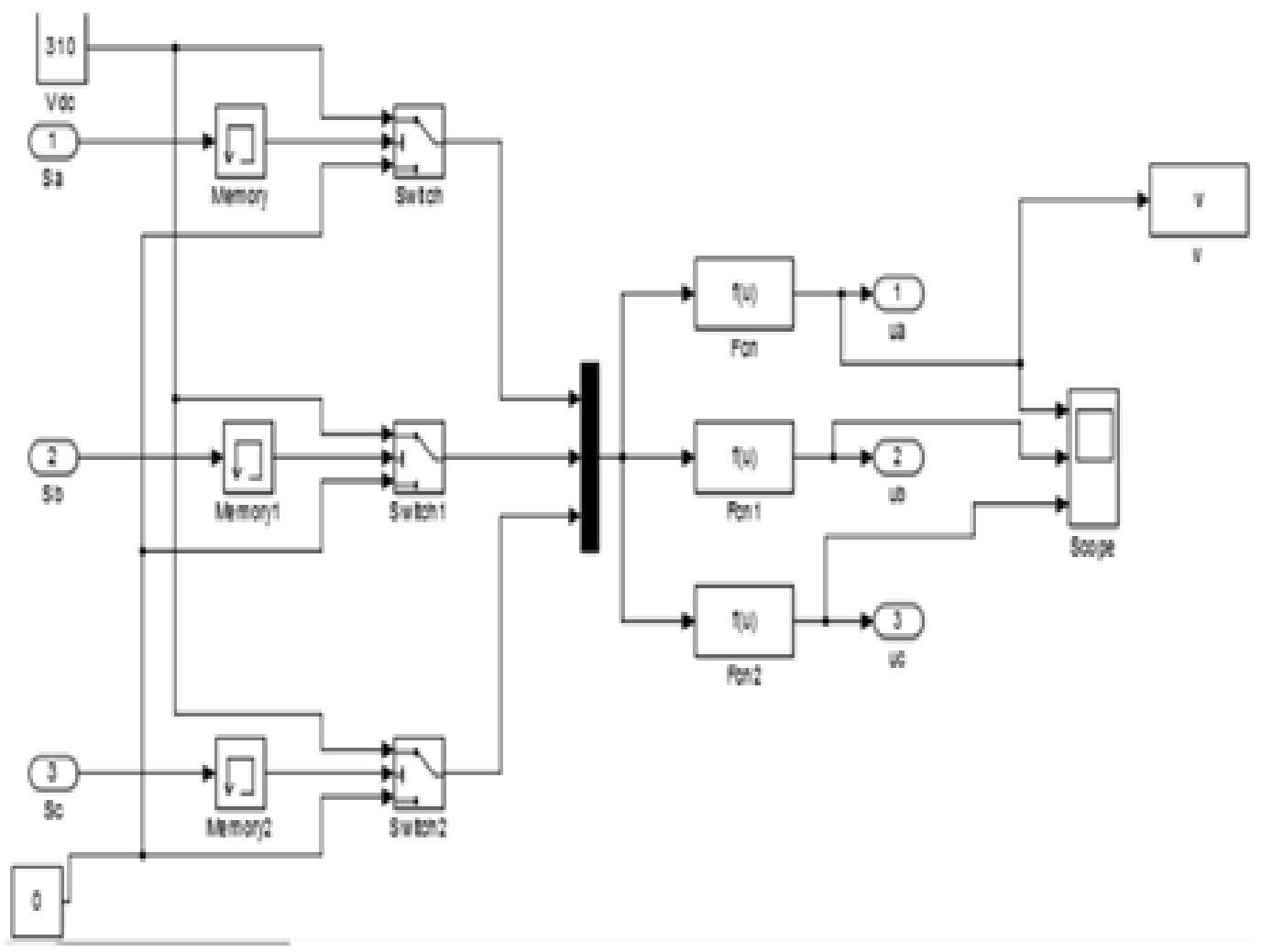

Figure 6. Three phase two level VSI in SIMULINK (MATLAB)

\subsection{PI Controller}

A PI controller is used to estimate the torque from the difference between the reference and actual speed of the motor [12] as shown in Figure 7. The parameters of PI controller $K_{p}$ and $K_{i}$ should be matched and to achieve the high performance of the drive system. The most of the cases, a large value of $K_{p}$ will accelerate the dynamic response of the system and $\mathrm{K}_{\mathrm{i}}$ value influence the static error.

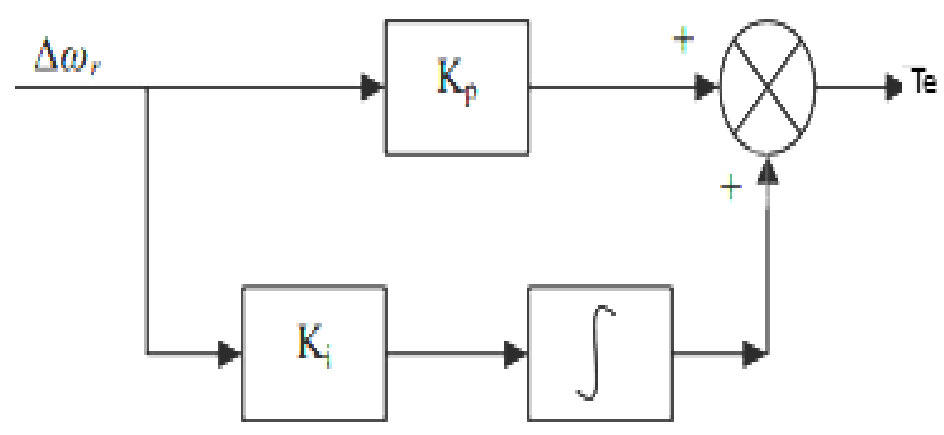

Figure 7. Block daigram of PI conroller 


\section{SIMULATION AND ANALYSIS OF RESULTS}

The overall system consisting of the modeling of SPMSM, estimation of stator flux and torque block, determination of sector, comparator, Vector modulation and three phase two level inverter which are modeled based on mathematical equations from equations (1) - (12). In this paper, the motor parameters are consider [9],[13],[14] as shown Table 1. The simulation block diagram for modified DTC for SPMSM with PI controller represented in below Figure 8.

Table 1. The Specification of SPMSM

\begin{tabular}{lcc}
\hline \multicolumn{1}{c}{ Motor Parameters } & Symbols & Values \\
\hline Stator Resistance & $\mathrm{Rs}$ & $2.875 \Omega$ \\
D Axis Inductance & $\mathrm{Ld}$ & $0.0085 \mathrm{H}$ \\
Q Axis Inductance & $\mathrm{Lq}$ & $0.0085 \mathrm{H}$ \\
Flux induced in SPMSM & $\lambda_{\mathrm{f}}$ & $0.175 \mathrm{wb}$ \\
Momentum of Inertia & $\mathrm{J}$ & $0.0008 \mathrm{Kg}-\mathrm{m}^{2}$ \\
Friction Factor & $\mathrm{B}$ & 0.0001 \\
Poles & $\mathrm{P}$ & 4 \\
\hline
\end{tabular}

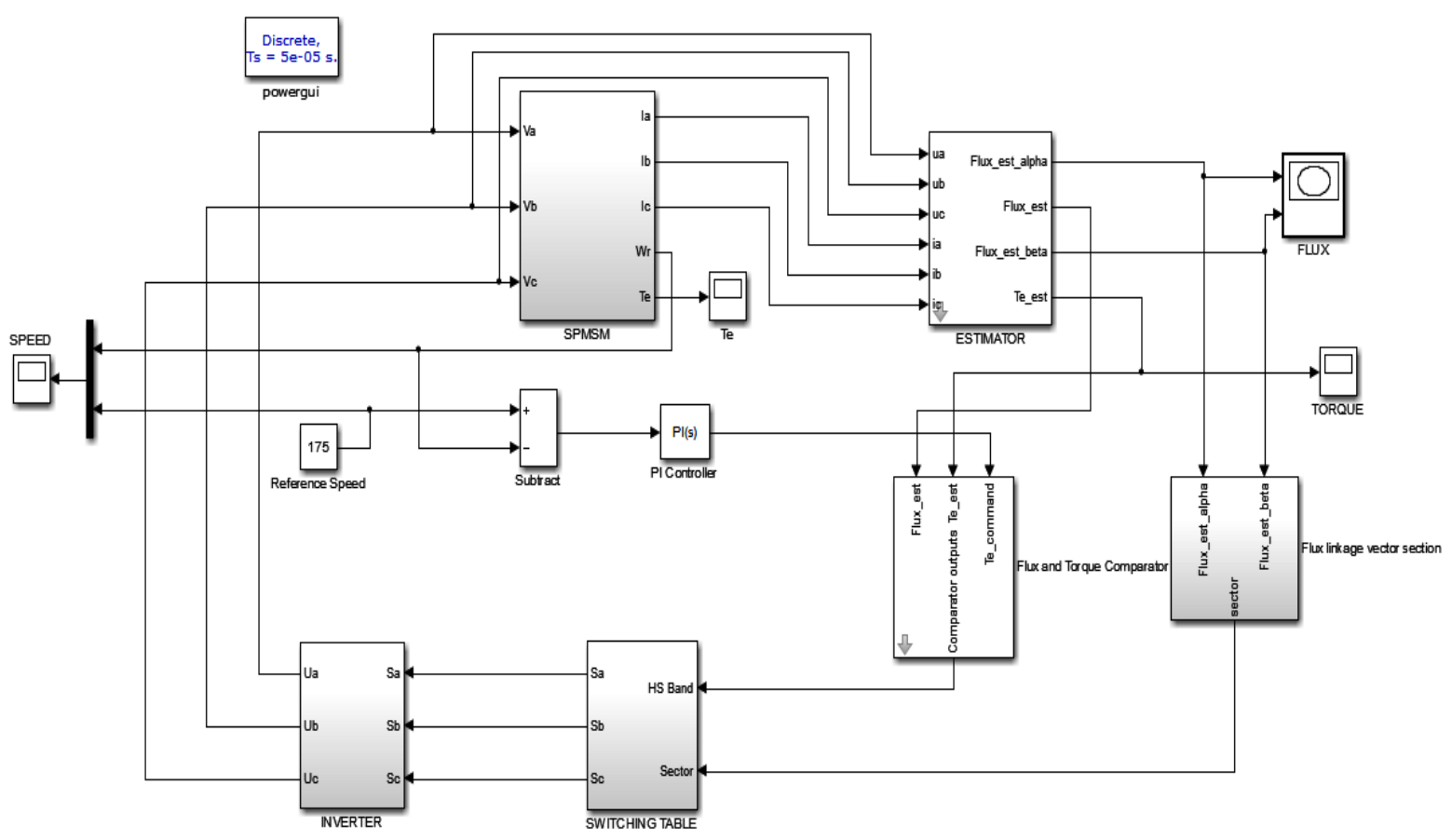

Figure 8. Simulation block diagram of modified DTC of SPMSM

By using MATLAB/ SIMULINK, The output waveforms of modified DTC for SPMSM are compared with the conventional DTC in view of speed performance with no load and load condition ,fluxlinkage, torque response and finally to estimate the perenetage of THD for stator current spectrum and as obvious in the Figure 9-16. From these figures, the generations of fluctuations in are greatly reduced and attaining reference speed immediately with load disturbance.

\subsection{Analysis the Speed Response of Modified DTC for SPMSM}

Figure 9 and 10 describes the speed response of modified DTC for SPMSM as well as conventional DTC.The both drives are operated with reference speed of $175 \mathrm{rads} / \mathrm{sec}$.for no load condition and load $6 \mathrm{Nm}$ is applied at $0.5 \mathrm{sec}$.In case of conventional DTC, The speed of the motor consisting oscillations whenever load is applied at $0.5 \mathrm{sec}$. and the system requires time to reach the reference speed. Wherein the modified DTC, the fluctuations of speed response is very less, in addition the same load applied at 0.5 sec. the drive attains to rated speed immediately as shown in Figure 10. 


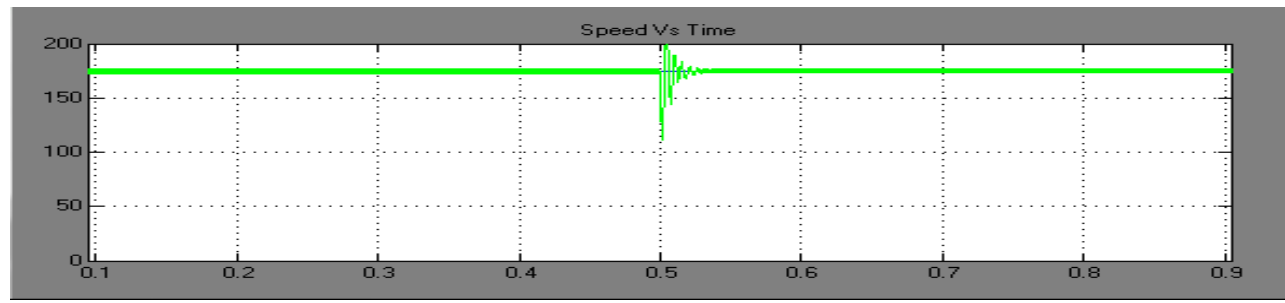

Figure 9. Speed response of conventional DTC for SPMSM with PI controller

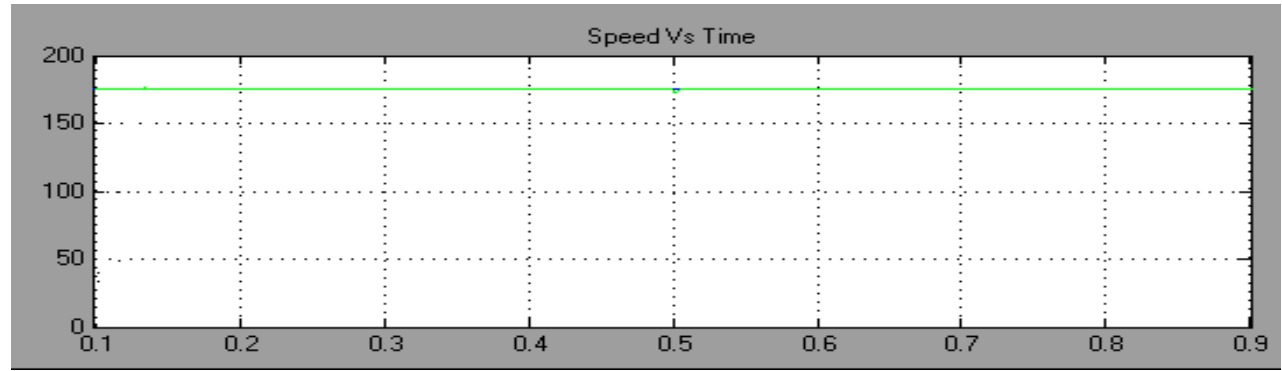

Figure 10. Speed response of modified DTC for SPMSM with PI controller

\subsection{The Estimated Stator Flux Vector}

The circular trajectory of stator flux vector of modified DTC and conventional DTC of SPMSM with PI Controller are shown as Figure 11 and 12. From these circles of stator fluxes, the content of ripples in the flux trajectory of the modified DTC method is very low and which is very smooth circle.

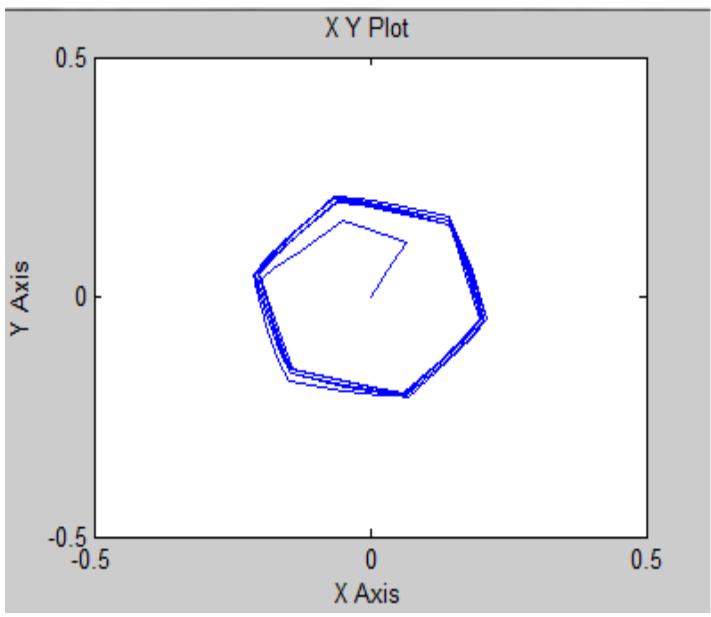

Figure 11. Conventional DTC of stator flux trajectory

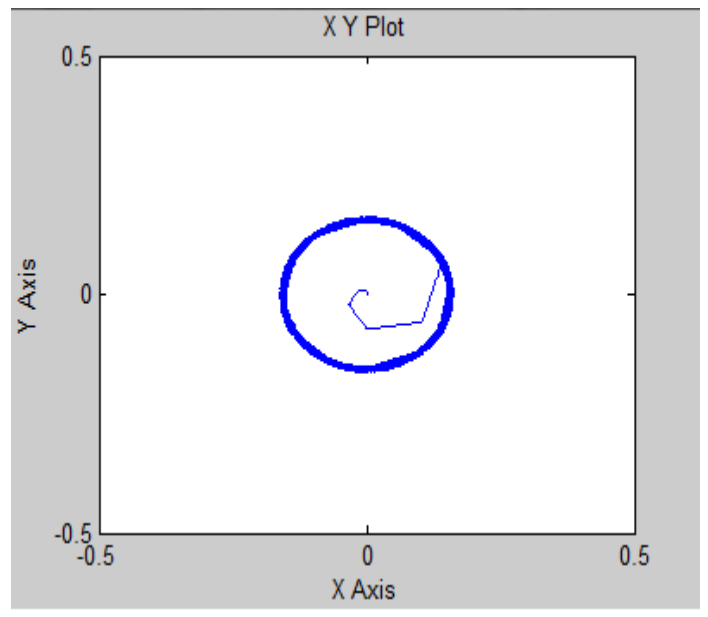

Figure 12. Modified DTC stator flux trajectory

\subsection{The Estimated Torque Response}

The torque responses of SPMSM with PI controller using three phase two level VSI at no load and load is applied $6 \mathrm{Nm}$ at $0.5 \mathrm{sec}$.as shown in Figure 13 and 14. Whereas the torque response of modified DTC for PMSM is achieved fast and the parcentage of ripples are low than the traditional DTC 


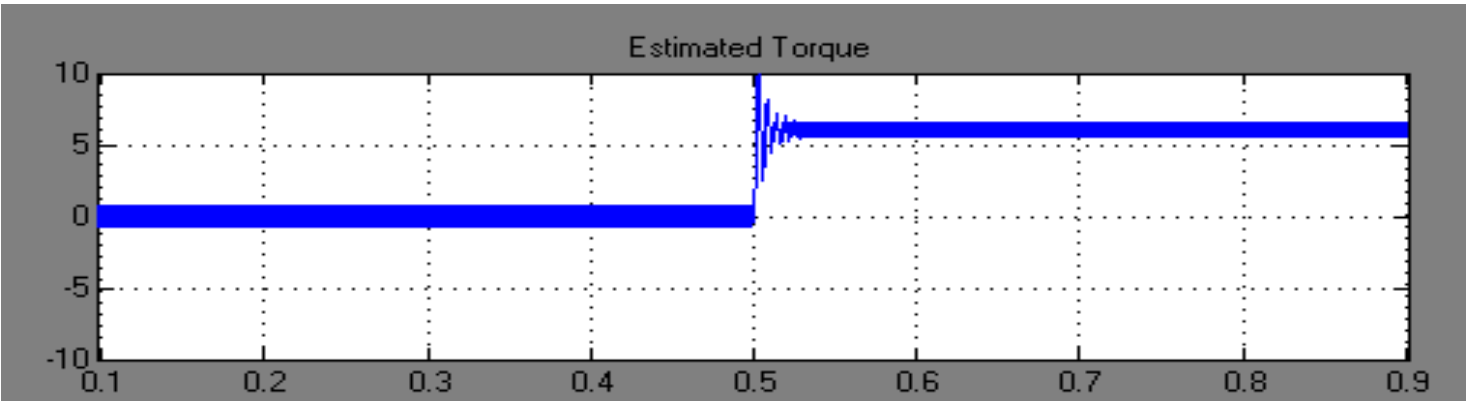

Figure 13. Estimated torque of conventional DTC for PMSM

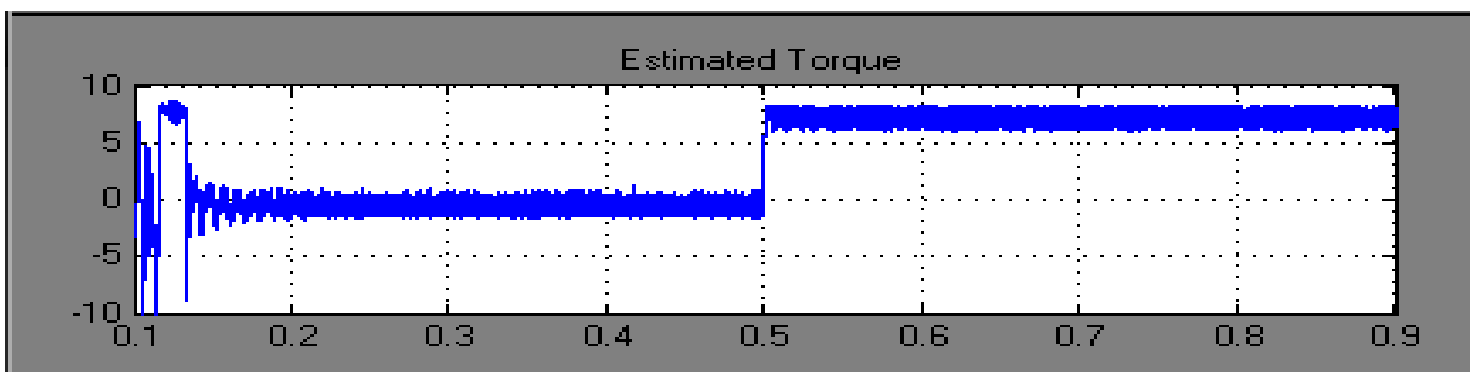

Figure 14. Estimated torque of modified DTC for PMSM

\subsection{The Estimated Percentage of THD for Stator Current Spectrum}

Finaly from the Figure 15 and 16, it observed that the FFT analysis of the current spectrum, in the modified DTC is observed that the percentage Total Harmonic Distortion (\%THD) can be calculated for the phase current vector of PMSM with PI Controller for 20 cycles with fundamental frequency and THD is recorded to be $31.84 \%$ which is less than conventional DTC $(52.78 \%)$.

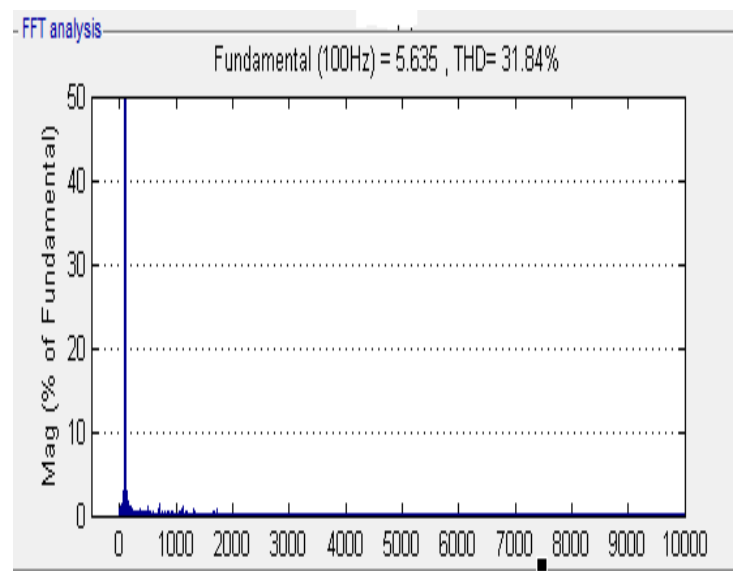

Figure 15. \% THD for Phase current Vector of MDTC

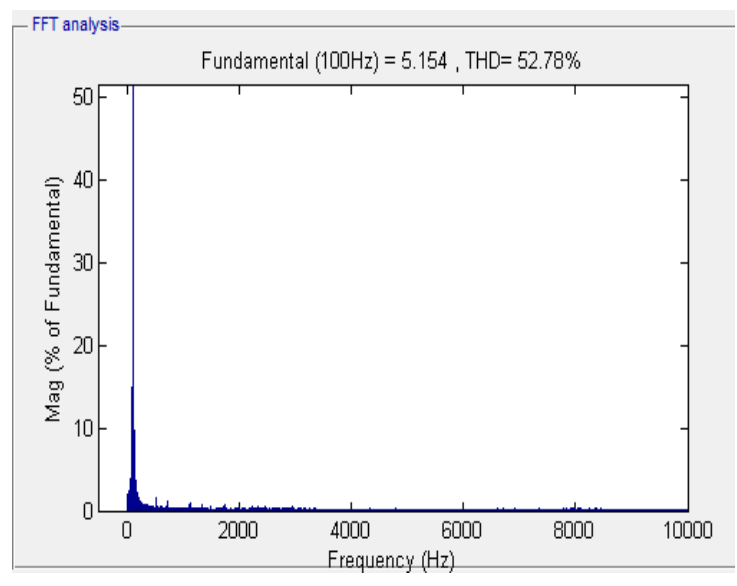

Figure 16. \% THD for Phase current vector of CDTC

The performance characterstics of SPMSM drive with different DTC using PI controller is summarized in Table 2. In which the modified DTC shcemes with fast and smooth responses with torque ripple $12.76 \%$ and $\%$ THD of stator winding phase current $31.84 \%$ as against to torque ripple $16.66 \%$ and $\%$ THD of stator current spectrum $52.78 \%$ of Conventional DTC. 
Table 2. Performane characterstics values of SPMSM with different DTC

\begin{tabular}{ccc}
\hline Type of DTC & Current \%THD & Torque Ripple (\%) \\
\hline Conventional DTC & $52.78 \%$ & $16.66 \%$ \\
Modified DTC & $31.84 \%$ & $12.76 \%$ \\
\hline
\end{tabular}

\section{CONCLUSION}

This paper describes the modified DTC algorithm of Sourface Mounted Permanent Magnet Synchronous Motor with PI controller which is considered with replacing of switching table selector block and hysteresis controllers of flux and torque.The simulation results have shown that the modified DTC gives better performance of transient and steady state operation than the conventional DTC. In fact, it has a significant reduction of the torque and flux ripples and the flux was indirectly controlled. In addition it can be obsevered that the percentage of THD for current spectrum is $31.84 \%$.It can be observed from the modified DTC which gives the smooth speed operation during transient and steady state conditions.

\section{REFERENCES}

[1] Y. Liu, "Space Vector Modulated Direct Torque Control for Pmsm," Spinger, CSISE, ASIC 105, pp. 225-230, 2011.

[2] M. Tursini, et al., "Feedforward Flux-Weakening Control of Surface-Mounted Permanent-Magnet Synchronous Motors Accounting for Resistive Voltage Drop,” IEEE Transactions on industrial electronics, vol/issue: 57(1), pp. 440-448, 2010.

[3] R. Sharma, et al., "Performance Analysis of Direct Torque Control of PMSM Drive Using Two Level Inverter," IEEE.Communication and network Technologies.

[4] M. Siami and S. A. Gholamian, "Application of Direct Torque Control Technique for Three Phase Surface Mounted AFPM Synchronous Motors," International Journal of Science and Advanced Technology, vol/issue: 1(10), pp. 15-20, 2011.

[5] S. Zhao and X. Peng, "A Modified Direct Torque Control Using Space Vector Modulation (DTC-SVM) for Surface Permanent Magnet Synchronous Machine (PMSM) with Modified 4- order Sliding Mode Observer," Proceedings of the 2007 IEEE International Conference on Mechatronics and Automation August 5 - 8, 2007, Harbin, China, pp. 1207-1212, 2007.

[6] S. B. Ozturk and H. A. Toliyat, "Sensorless Direct Torque and Indirect Flux Control of Brushless DC Motor with Non Sinusoidal Back EMF," IEEE.

[7] H. Xu-chao and L. Rong-wen, "Novel design for Direct Torque Control System of PMSM," TELKOMNIKA, vol. 11, pp. 2012-2109, 2013.

[8] M. Boujemaa and C. Rachid, "Field Oriented Control of PMSM Supplied by Photovoltaic Source," International Journal of Electrical and Computer Engineering (IJECE), vol/issue: 6(3), pp. 1233-1247, 2016.

[9] S. V. Paturca, et al., "Direct Torque Control of Permanent Magnet Synchronous Motor (PMSM)- an approach by using Space Vector Modulation (SVM)," Proce. Of the $6^{\text {th }}$ WSEAS/IASME int. Conf. on Electric power Systems, 2006.

[10] Z. Lu, et al., "The modeling and Simulation of a Permanent magnet Synchronous Motor with Direct torque control based on a Matlab/Simulink," IEEE.

[11] C. E. Dahmani, et al., "Direct Torque Control of Permanent Magnet Synchronous Motors in MATLAB/ SIMULINK," IEEE, ICCEIT, 2016.

[12] A. S. Tomer and S. P. Dubey, "Response Based Comparative Analysis of Two Inverter Fed Six Phase PMSM Drive by using PI and Fuzzy logic Controller," IJECE, vol. 6, pp. 2643-2657, 2016.

[13] Z. Zhang and J. Shu, "Matlab-based Permanent Magnet Synchronous Motor Vector Control Simulation," IEEE, ICCSIT, 2010.

[14] Z. Haigang, et al., "Modeling and Simulation of a Permanent magnet Synchronous Motor Drive," IEEE, 2011. 


\section{BIOGRAPHIES OF AUTHORS}
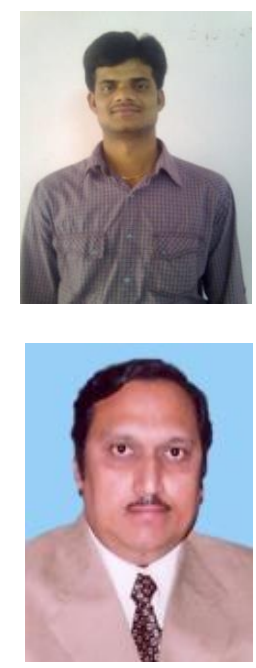

Mr. D. Kiran Kumar was born on $3^{\text {rd }}$ june, 1984 in Guntur, A.P, India. He was graduate in Electrical and Electronics Engineering from SCREC in 2007. He was obtained post graduate in VLSI Design from Bharath University, Chennai in 2009.Presently he was working as Assistant Professor in the deparment of Electrical and Electronics Engineering, JNTUH College of Engineering hyderabad,since 2010 and persuing Ph.D at JNT University, Hyderabad . His research interests are Electrical Drives,FACTTS, Power Quality, Multilevel Inverters and VLSI Design.

Dr. G. Tulasi Ram Das has received his B.Tech degree in Electrical \& Electronics Engineering from J.N.T.U. College of Engineering, Hyderabad, India in 1983, M.E. degree with Industrial Drives \& Control from O.U College of Engineering, Hyderabad, India in 1986 and received his Ph.D. degree from the Indian Institute of Technology, Madras, India in 1996. He is having 30 years of teaching and research experience. He held positions of J.N.T. University Hyderabad, Registrar of JNT University Hyderabad, Vice-Chancellor, JNTU Kakinada and currently Professor in EEE Department, JNTUHCEH. He has supervised 21 Ph.D. theses and 10 Ph.D. theses are under progress. He has published/presented 152 technical research papers in national and international conferences and journals. He has visited countries namely, Singapore, Malaysia, USA, KSA, UAE and UK. He is a Fellow of Institute of Engineers (India), (FIE), Fellow of Institute of Electronics \& Telecommunication Engineering (FIETE), Member of IEEE (MIEEE), Member of Solar Energy Society of India (MSESI) and Member of Indian Society for Technical Education (MISTE). He is a recipient of "BEST TEACHER STATE AWARD FOR THE YEAR 2009" announced by the Govt. of Andhra Pradesh. He has received the award from the Chief Minister of Andhra Pradesh. Research Interests include: Simulation studies on drives for Permanent Magnets Synchronous Machines, Electrical Machines \& Special Machines, Resonant Converters, FACTS, Power quality, AI applications to Power Systems and Drives.

E-mail: das_tulasiram@yahoo.co.in 